\title{
MENINGKATKAN KETERAMPILAN GURU SMK MENGGUNAKAN APLIKASI CAD DI SMK ISAM SABILAL MUHTADIN
}

\author{
Rendi, Jainal Arifin, Firda Herlina, Sobar Ihsan, Budi Hartadi, \\ dan Gusti Rusdy Furqon Syahrillah \\ Program Studi Teknik Mesin, Fakultas Teknik, Universitas Islam Kalimantan \\ E-mail : rendi.teknikmesin@gmail.com
}

\begin{abstract}
ABSTRAK
Tujuan program pengabdian adalah memberikan pelatihan Software AutoCAD untuk guru-guru dan siswa-siswi SMK Islam Sabilal Muhtadin dan melakukan pedampingan kepada guru pembelajaran gambar teknik. Sasaran pengabdian kepada masyarakat ini, adalah guru SMK Islam sabilalmutadin yang mengajar gambar mesin. Kegiatan menggunakan metode pelatihan langsung (hands on) berupa pemaparan/presentasi, tutorial serta diskusi. Monitoring dan Evaluasi dilakukan bagi yang telah mengikuti kegiatan, metode yang digunakan dalam monitoring dan evaluasi adalah memberikan peserta tugas menggambar kemudian kami catat waktu yang butuhkan untuk menyelesaikan tugas gambar tersebut. Hasil evaluasi paling lama- lama peserta menyelesaikan tugas gambar adalah 35 menita dan yang paling cepat adalah 20 menit. Rata-tara peserta mampu menyelesaikan tugas gambar selama 27.09 menit. Dari hasil evaluasi ini dapat dikatakan bahwa semua pesereta pelatihan sudah mampu menggambar teknik dengan aplikasi AutoCad dengan baik dapat dikatakan juga keterampilan mereka sudah jauh meningkat dari yang awalnya tidak bisa menjadi bisa.
\end{abstract}

Kata Kunci : Autocad, Peserta pelatihan, Evaluasi

\section{PENDAHULUAN}

\section{CAD (Computer Aided Design)}

adalah suatu program komputer untuk menggambar. Salah satu software CAD yang pling banyak digunakan di dunia kerja industri dan teknik adalah softeare Auc Cad

Salah satu program yang dicanangkan oleh pemerintah melalui kementrian pendidikan dan kebudayaan adalah program "SMK Bisa". Melalui program "SMK Bisa" pemerintah berharap dapat menciptakan tenagatenaga kerja siap pakai. Akan tetapi, lulusan SMK di Indonesia masih dipandang kurang berkompeten oleh dunia usaha. Perihal tersebut menjadi tantangan pemerintah, Pemerintah harus menciptakan tenaga terdidik yang berkompeten agar peserta didik (siswa dan siswi) bisa bersaing di dunia industri, maupun pasar bebas Asia pasifik.

Banyak atau sedikitnya ketermapilan siswa tergantung kemampuan para guru dalam mendidik dan mengembangkan potensi yang dimiliki oleh siswa. Bagi jurusan 
keteknikan, menguasai gambar teknik menjadihal yang mutlah baik gambar teknik secara manual maupun dengan bantuan software CAD. Kemajuan teknologi yang terus berkembang pada akhirnya nanti penggunaan gambar teknik secara manual tidak begitu di minati oleh dunia kerja, dengan demikian bearti seorang siswa nantinya memang harus menguasai software CAD untuk menggambar teknik. Untuk mencapai itu maka dibutuhkan guruguru SMK yang menguasai software CAD dengan baik supaya guru-guru tersebut bisa mengajarkannya ke siswa pada saat mata pelajaran gambar teknik.

Mitra pada gegiatan pengabdian kepada masyarakat ini adalah SMK Sabilal Muhtadin Banjarmasin. Yang berlokasi di Banjarmasin. Di SMK mitra terdapat 3 jurusan yaitu 1) Teknik Bisnis Sepeda Motor, 2) Teknik Komputer jaringan, 3) dan Teknik perkantoran, Dalam program pengabdian kepada masyarakat ini guruguru yang menjadi target pengabdian kepada masyarakat adalah guru-guru jurusan Teknik Bisnis Sepeda Motor (TBSM) hal ini dikarenakan pada jurusan ini ada beberapa mata pelajaran gambar mesin.
Berdasarkan wawancara dengan salah satu guru Teknik Bisnis Sepeda Motor (TBSM) Sabilal Mutadin penggunaan software CAD belum di terapkan selama ini gambar mesin di praktekan hanya secara manual. Salah satu alasan belum di terapkannya adalah guru-guru guru yang mengajar gambar teknik belum menguasai software CAD dengan baik.

Tujuan kegiatan pengabdian masyarakat kali imi adalah

1. Memberikan pelatihan Software AutoCAD untuk guru-guru dan siswa-siswi SMK Islam Sabilal Muhtadin desain permodelan berupa gambar-gambar permesinan dalam bentuk 2 dimensi dan 3 dimensi

2. Melakukan pedampingan kepada siswa-siswi SMK dalam pola pembelajaran gambar teknik dengan mentoring dan penyedian modul

3. Menambah koleksi perpustaakan SMK dengan memelikan buku-buku Auto Cad

Dengan adanya pengabdian kepada masyarakat ini harapannya adalah para guru gambar teknik mulai menerapkan penggunaan software CAD dalam menggambar mesin. 


\section{METODE}

Metode pelaksanaan kegiatan pengabdian kepada masyarkat untuk menyelesaikan permasalahan mitra adalah dijelaskan pada skema berikut :

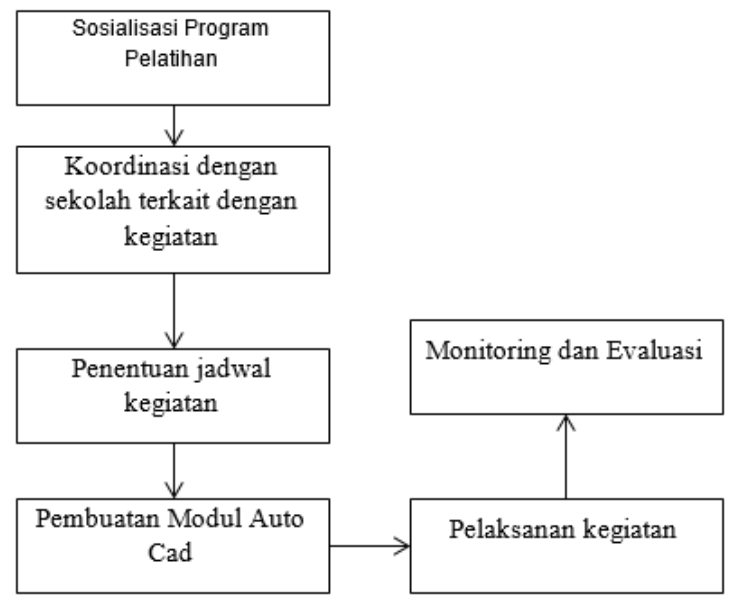

Gambar 1 Skema alur kegiatan

Pemberian materi pelatihan software AutoCAD, dapat dirinci sebagai berikut:

a. Materi Kompetensi Pelatihan AutoCAD adalah materi AutoCAD 2D dan 3D (3D modelling), antara lain: materi pengaturan layar kerja (workspace AutoCAD), pengenalan toolbar dan perintah (command AutoCAD), membuat custom interface \& toolbar AutoCAD, cara pelatihan diberikan materi-materi secara ceramah dan demonstrasi langsung tentang penerapan software AutoCAD pada penggambaran yang berhubungan dengan bidang teknik.

b. Pembuatan modul pelatihan c. Memberikan buku-buku CAD, Untuk mendukung kegiatan kami berjalan dengan lancar makakami memberikan buku-buku CAD kepada mitra. Buku- buku yang akan kami berikan di antaranya : Buku Auto Cad 2d dan Buku Autocad 3d

\section{HASIL DAN PEMBAHASAN}

Pelaksanaan kegiatan program pengabdian masyarakat ini dilakukan di Laboratorium Teknik Komputer yang terdapat diseklah SMK Islam Sabilal Muhtadin dengan jumlah peserta keseluruhan adalah 11 orang yang terdiri dari 3 orang guru Teknik bisnis Sepeda Motor (TBSM) dan 8 orang siswa jurusan Teknik bisnis Sepeda Motor (TBSM)

Dalam pelaksanaannya, kegiatan ini menggunakan metode pelatihan langsung (hands on) berupa pemaparan/presentasi, tutorial serta diskusi.

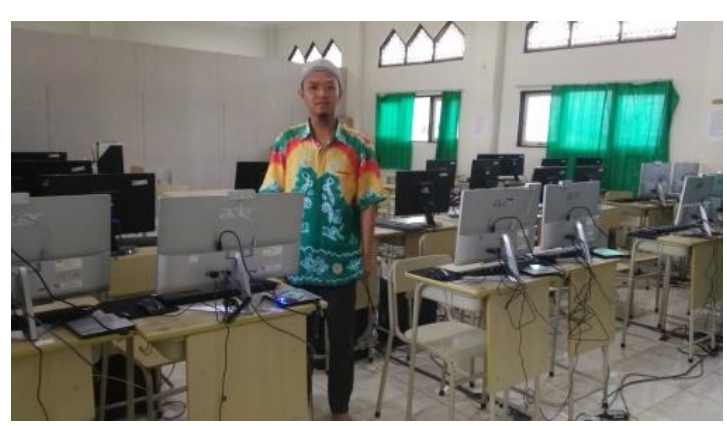




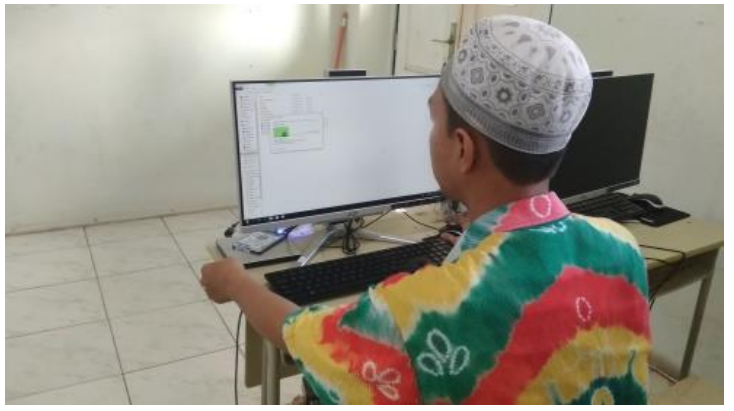

Gambar 2 Tim melakukan penginstalan Software Auto Cad ke Komputer Mitra
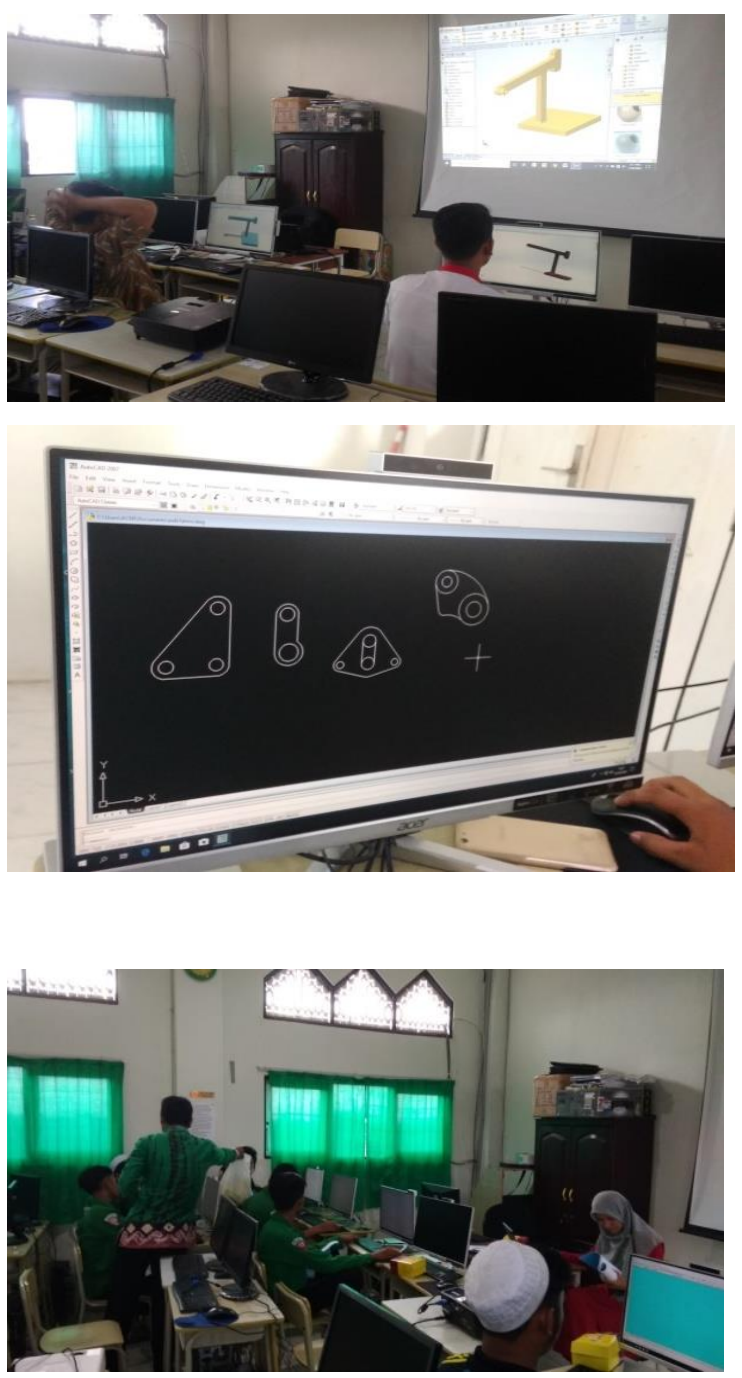

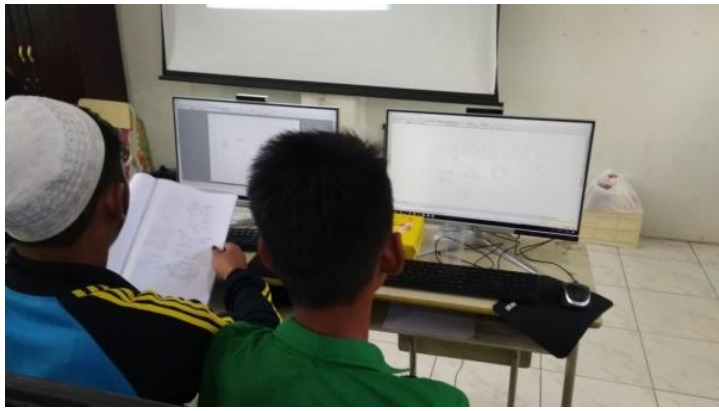

Gambar 3 Prrsentasi dan totorial

AutoCad.

Sealain persentasi secara langsung, tim juga menyediakan tutorial lewat link yutube yang bisa di download oleh peserta pengabdian dengan nama chenal yutub Catatan Kuliah Rendi di laman https://www.youtube.com/watch?v=_v NB_0oqTnM

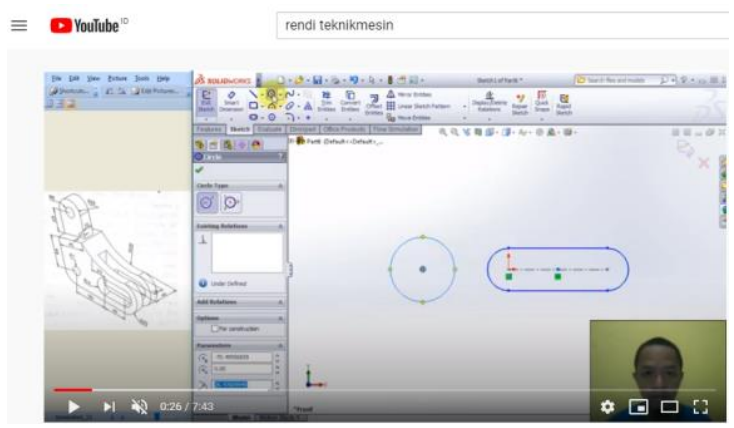

Gambar 4.

Hasil capain yang sudah dilaksanakan dan sudah tercapai adalah sebagai berikut:

1. Sosialisasi kegiatan pengabdian masyarakat terkait dengan program pelatihan AutoCAD

2. Pelatihan software AutoCAD, dalam pelaksanaan dibagi menjadi 2 bagian yaitu pelatiahn guru dan pelatihan 
siswa. Pelaksanaan pelatihan berlangsung selama 5 hari yaitu pada tanggal 28 januari 2020, 04 februari, 11 februari, 18 februari, dan 25 februari 2020 dengan interval waktu dari jam 12.30 - 16.00 WIB. Terkait dengan hasil desain yang dihasilkan selama program pelatihan AutoCAD dapat dilihat pada gambar sebagai berikut:

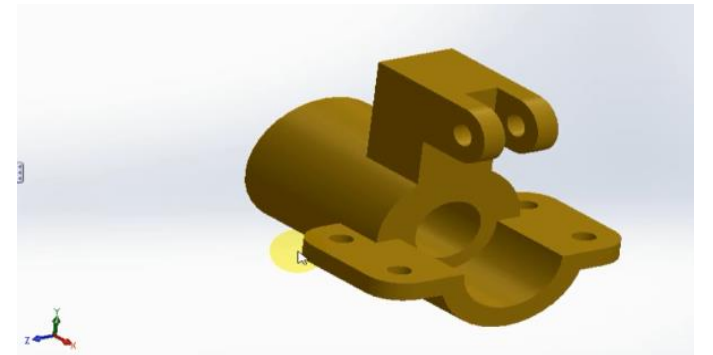

Gambar 5. Hasil Proses Gambar AutoCAD

3. Memberikan modul pelatihan dan melaksanakan evaluasi pelatihan dilakukan pada akhir sesi pelatihan dengan peserta diberi tugas untuk menyelesaikan gambar dengan mengunakan software yang terkait.

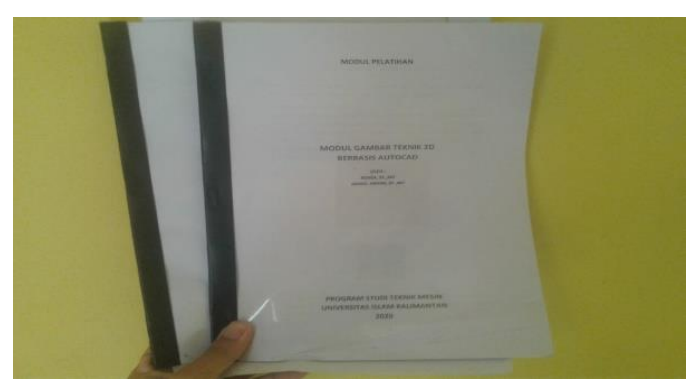

Gambar 6. Modul Pelatihan dengan Software AutoCAD
4. Monitoring dan Evaluasi dilakukan bagi yang telah mengikuti pelatihan AutoCAD. Kegiatan yang dilakukan untuk mengetahui apakah keterampilan peserta sudah meningat. Metode yang dilakukan dalam monitoring dan evaluasi adalah dengan memberikan peserta tugas menggambar kemudian kami catat berapa lama waktu yang mereka butuhkan untuk menyelesaikan tugas gambar tersebut.

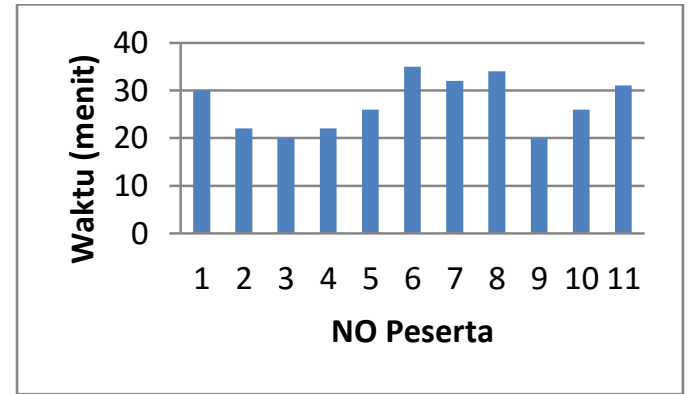

Gambar 7. Grafik persentasi keberhasilan peserta

Dari gambar grafik ini terlihat bahwa, paling lama peserta menyelesaikan tugas gambar adalah 35 menita dan yang paling cepat adalah 20 menit. Rata tara peserta mampu menyelesaikan tugas gambar selama 27.09 menit. Dari hasil evaluasi ini dapat dikatakan bahwa semua pesereta pelatihan sudah mampu menggambar teknik dengan aplikasi AutoCad dengan baik dapat dikatakan juga keterampilan 
mereka sudah jauh meningkat dari yang awalnya tidak bisa menjadi bisa.

\section{KESIMPULAN}

Berdasarkan keteranganketerangan yang telah dipaparkan sebelumnya, dapat disimpulkan bahwa:

1. Masih perlunya kegiatan pelatihan secara berkesinambungan kepada guru dan siswa-siswi SMK Islam Sabilal Muhtadin, agar pembelajaran yang berorientasi pada pasar kerja dapat terus dtingkatkan.

2. Perlunya program AutoCAD untuk jurusan Teknik bisnis sepeda motor (TBSM) dalam kurukulum gambar teknik yang bertujuan untuk peningkatan kompetensi siswa, agar mampu bersaing di pasar dunia siap kerja

\section{DAFTAR PUSTAKA}

Atmajayani, Risma Dwi.2018. "Implementasi Penggunaan Aplikasi AutoCAD dalam Meningkatkan Kompetensi Dasar Menggambar teknik bagi Masyarakat" Jurnal Riset dan Konseptual. Volume 3 Nomor 2. Pp 184-189

Frida,Muthia.2019.

"Pelatihan Penggunaan Microsoft Excel Untuk Perhitungan Nilai Siswa Pada Mts. Al-Furqon Banjarmasin” Jurnal :Al Ikhlas. Vol 5. No 1.pp 96-100

Juhana, Ohman dan Sutarman. 2008. "Menggambar Teknik Mesin". Jakarta : Pustaka setia

Nurkhin,Ahmd. Dkk.2020 "Program Peningkatan Kompetensi Wirausaha Halal Food Bagi Santri Tahfidz".Jurnal :Al Ikhlas. Vol 5. No 2.pp 107-117

Putera,Zko Pratama.2014. "Autocad 2014 Untuk Pemula". Jakarta : Erlangga

Ramadhan, alli dan Hady Soedarwanto.2017. "Pelatihan Penggunaan Software AutoCAD Bentuk 3 Dimensi Sebagai Pelengkap Gambar Kerja" Universitas Mercu Buana Jakarta. 